\title{
Low-dose radioisotope scanning and quantitative analysis in the diagnosis of congenital hypothyroidism
}

\author{
M K O'CONNOR, P J FREYNE, AND M J CULLEN \\ Department of Radiology/Nuclear Medicine, St James's Hospital, Dublin
}

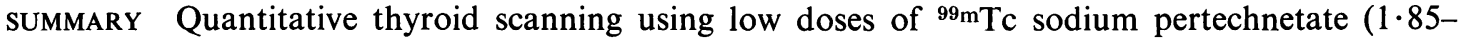
$3.7 \mathrm{MBq}$ ) was performed in 38 cases of congenital hypothyroidism. Of these 38 cases, 29 were scanned at $14 \pm 6$ days old, and 9 at 1 year old. The scans show the full range of gland anatomy from athyreotic to normal. All morphologically normal scans had grossly increased uptakes of ${ }^{99 \mathrm{~m} T c}$. The incidence of the various thyroid anatomies was different in each age group. The average radiation dose to the thyroid was $2.29 \mathrm{mGy}$, with at least $70 \%$ of patients receiving a dose of $3.0 \mathrm{mGy}$ or less. Such low doses of $99 \mathrm{~m}$ Tc should allow further scanning in later life. Neonatal thyroid scanning reveals the aetiology of congenital hypothyroidism and enables the clinician to assess the short- and long-term needs of the child.

Untreated congenital hypothyroidism (CHT) causes mental handicap and probably infants with CHT comprise the largest remaining group for whom specific and effective treatment is available. Screening programmes for CHT were started in 1974 and now exist in over 70 centres throughout the world. ${ }^{12}$ They are of considerable value; not only do they improve the quality of life for the affected infant, but they also save money, for the country is no longer faced with the maintenance of a retarded child. ${ }^{2}$

Although it has been recommended that thyroid scanning should be included in screening programmes, Fisher ${ }^{1}$ reported that only $30 \%$ of infants with CHT have received ${ }^{99} \mathrm{~m}$ Tc scans in the USA, and there is no information on how long after birth such scans were performed. Connolly et al. ${ }^{3}$ reported on the feasibility of neonatal thyroid scanning before treatment, and concluded that scanning was useful in permitting treatment to be started with confidence. However, in neither of these studies was any quantitative information on gland uptake given. Knowledge both of function and anatomy may be important for the welfare of the child, and to evaluate retrospectively the benefit of screening programmes. ${ }^{24}$

We describe a low-dose scanning technique that provides anatomical and functional information on the neonatal thyroid; it also provides an estimate of the absorbed dose to the thyroid.

\section{Methods}

Measurement of thyroid-stimulating hormone (TSH) levels in the neonates was performed using filter paper dried blood spots taken from standard Guthrie cards used for phenylketonuria screening. ${ }^{5}$ If a raised TSH level was found confirmation was sought from serum TSH. If this was positive too, a thyroid scan was arranged, generally within 24 hours and certainly not longer than 48 hours later. Hormone replacement therapy was started immediately after scanning.

For thyroid scanning, the neonate was placed in a polystyrene radiolucent immobiliser which was moulded to the shape of the infant (Hold and Mold immobilizer, Nuclear Associates Ltd). This restraint was well tolerated by every neonate and no sedation was necessary. During the first 3-6 months of the CHT screening programme, the dose of ${ }^{99 \mathrm{~m} T c}$ sodium pertechnetate used was in the range 5.67.4 MBq $(150-200 \mu \mathrm{Ci})$. This dose is considerably lower then the 18-74 MBq $(0 \cdot 5-2 \cdot 0 \mathrm{mCi})$ dose used in other studies, ${ }^{36}$ and is in line with that currently recommended. ${ }^{7}$ However, experience has shown that long scanning times of 30 minutes are sometimes necessary and subsequently doses were reduced to 1.85-3.7 MBq (50-100 $\mu \mathrm{Ci})$.

The ${ }^{99 m}$ Tc sodium pertechnetate was administered intravenously. The radioactivity in the syringe was measured both before and after injection to give the corrected administered dose. Scanning was performed using a General Electric Maxi II Gamma camera together with a pinhole collimator. The images were stored on computer as $30 \times 1 \mathrm{~min}$ frames with a Matrix size of $64 \times 64$ elements. 
Scanning was started 3-5 minutes after injection at a pinhole to neck distance of $9 \mathrm{~cm}$. This ensured that the area of the body from the nose to the diaphragm could be seen in every case. If thyroid tissue was evident, the uptake of pertechnetate by the tissue was calculated using standard computer techniques. ${ }^{8}$ A standard injection of ${ }^{99 \mathrm{~m} T c}$ corrected to the administered dose was counted at a depth of $1 \mathrm{~cm}$ in Perspex. All functioning tissue was assumed to be at a depth of $1 \mathrm{~cm}$ below skin surface. No adjust- ments were made to allow for variations in gland depth or non-uniformity of response across the detector face. ${ }^{9} 1019$

Because the start of the scanning programme was delayed some neonates were not scanned until 1 year old, but the procedure was identical except that a small increase in the dose of ${ }^{99 \mathrm{~m}} \mathrm{Tc}$ from 1.93.7 to $3.7-5.6 \mathrm{MBq}$ was found to be necessary. In all infants hormone replacement therapy was changed from thyroxine to triiodothyronine 4 weeks
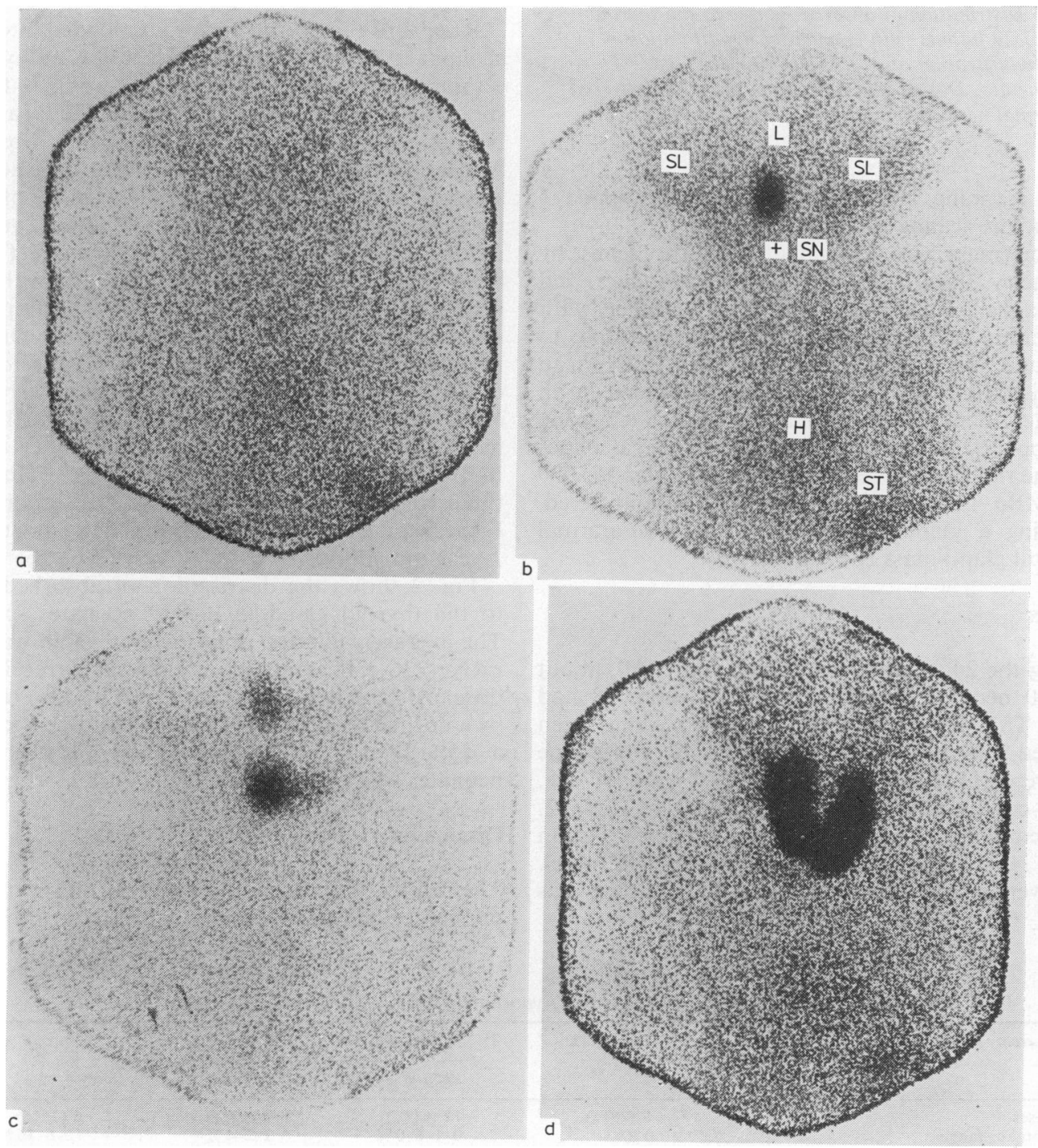

Fig. $1{ }^{99 \mathrm{~m}}$ Tc-sodium pertechnetate scans of neonates with congenital hypothyroidism, (a) athyreotic, (b) lingual thyroid, $(c)$ lingual + sublingual thyroid tissue, and $(d)$ 'normal' enlarged thyroid. Anatomical features shown in Fig. $1 \mathrm{~b}$ are, $S L=$ salivary glands, $L=$ lingual thyroid tissue, $H=$ heart, $S T=$ stomach, and $S N=$ sternal notch. 


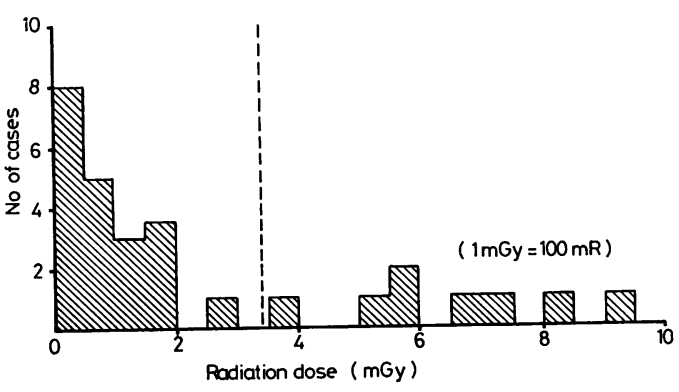

Fig. 2 Distribution of absorbed doses to the thyroid glands of 29 infants with congenital hypothyroidism after administration of $3.7 \mathrm{MBq}(100 \mu \mathrm{Ci})$ of ${ }^{99} \mathrm{~m} \mathrm{Tc}$ pertechnetate. Dotted line represents the dose delivered to a normal neonatal thyroid.

before scanning and all treatment was stopped 1 week before scanning.

Gland mass was estimated from the scans by planimetry using the method of Mandart and Erbsmann. ${ }^{11}$ From this estimate, together with the amount of gland uptake, the absorbed dose to the gland was estimated. For intercomparison an administered dose of $3.7 \mathrm{MBq}$ was assumed in all neonates. The radiation doses were estimated using the tabulated data of Roedler et $^{\text {al. }}{ }^{7}$ This calculates that the radiation dose to the euthyroid gland is 920 $\mu \mathrm{Gy} / \mathrm{MBq}(3.4 \mathrm{mR} / \mu \mathrm{Ci})$ of ${ }^{99 \mathrm{~m}} \mathrm{Tc}$ administered, assuming a gland uptake of $3.5 \%$. The normal neonatal gland mass is $1.9 \mathrm{~g}^{12} 13$

\section{Results}

During the 24-month period from July 1979, about 150000 neonates were screened of whom 38 had raised TSH levels. Of these 38 cases, 9 had been detected before the start of the scanning programme and were subsequently scanned at 1 year of age. These cases are presented separately in Table 2 . The remaining 29 neonates were scanned within 24-48 hours of the confirmed raised TSH level. The average age of the neonates at scanning was $14 \cdot 3 \pm 6 \cdot 1$ days.
Table 2 Comparison of distribution of various thyroid anatomies seen in neonates with congenital hypothyroidism

\begin{tabular}{|c|c|c|c|c|c|c|}
\hline \multirow[t]{2}{*}{ Study } & \multicolumn{2}{|c|}{ Normal } & \multicolumn{2}{|c|}{ Ectopic } & \multicolumn{2}{|c|}{ Athyreotic } \\
\hline & No & $(\%)$ & No & $(\%)$ & No & $(\%)$ \\
\hline This study (neonates) & 6 & (21) & 15 & (52) & 8 & (28) \\
\hline (1-year olds) & 0 & (0) & 3 & (33) & 6 & (67) \\
\hline Connolly et al. (neonates) & 3 & (13) & 13 & (54) & 8 & (33) \\
\hline Walfish et al. (neonates) & 5 & (26) & 9 & (48) & 5 & (26) \\
\hline Fisher (0-1 year approx) & 16 & (12) & 35 & (28) & 74 & (60) \\
\hline
\end{tabular}

Results of the thyroid scans are divided into three groups according to anatomical location-athyreotic, ectopic, and normal. The ectopic group is further subdivided into lingual and sublingual (Table 1). No intrathoracic thyroid tissue was observed. A series of scans is presented in Fig. 1 together with a typical scan from each group. The range of gland uptakes, the thyroxine and TSH levels, and the number of cases in each group are shown in Table 1. Scan findings in this series are compared with those reported elsewhere (Table 2). ${ }^{36}$ For this comparison all ectopic thyroids are grouped together. Only the findings of Connolly et al. ${ }^{3}$ and Walfish et al. ${ }^{6}$ are directly comparable, as those of Fisher ${ }^{1}$ were from cases scanned at various times after birth. The incidence of thyroid anatomies in neonates is similar in this study to that reported elsewhere. ${ }^{36}$ However, these results differ greatly from those reported by Fisher ${ }^{1}$ and from the results observed in our study for 1 -year-old infants.

Fig. 2 shows the distribution of absorbed doses to the thyroid gland in the 29 neonates scanned. The average radiation dose to the thyroid was $2 \cdot 36$ mGy $(236 \mathrm{mR})$ with more than $70 \%$ receiving a dose of $3.0 \mathrm{mGy}(300 \mathrm{mR})$ or less. The dose received by a normal thyroid is $3.4 \mathrm{mGy}(340 \mathrm{mR})$, shown by a dotted line. ${ }^{714}$ The whole-body dose in these neonates was about $0 \cdot 14 \mathrm{mGy}(14 \mathrm{mR}) .^{14}$

\section{Discussion}

The results of the scans showed the full spectrum of possible gland anatomies ranging from athyreotic

Table 1 Thyroid results in 29 neonates with congenital hypothyroidism

\begin{tabular}{|c|c|c|c|c|}
\hline \multirow[t]{2}{*}{ Gland anatomy } & \multirow[t]{2}{*}{ Athyreotic } & \multicolumn{2}{|l|}{ Ectopic } & \multirow[t]{2}{*}{ Normal } \\
\hline & & Lingual & Sublingual & \\
\hline $\begin{array}{l}\text { No of cases } \\
99 \mathrm{mTc} \text { uptake, range } \\
\text { (mean } \pm \text { SD) } \\
\text { Thyroxine (nmol/l), range } \\
\text { (mean } \pm \text { SD) } \\
\text { Thyroid-stimulating hormone }(\mathrm{mU} / \mathrm{l}) \text {, range }\end{array}$ & $\begin{array}{l}8(28 \%) \\
0 \% \\
28-68 \\
(38 \cdot 3 \pm 20 \cdot 8) \\
180-1220\end{array}$ & $\begin{array}{l}12(41 \%) \\
0 \cdot 1-6 \cdot 0 \% \\
(1 \cdot 1 \pm 1 \cdot 6 \%) \\
26-145 \\
(70 \pm 33) \\
106->200\end{array}$ & $\begin{array}{l}3(10 \%) \\
2 \cdot 2-4 \% \\
(3 \cdot 1 \pm 0 \cdot 9 \%) \\
46-171 \\
(90 \cdot 7 \pm 69 \cdot 7) \\
61->182\end{array}$ & $\begin{array}{l}6(21 \%) \\
12 \cdot 6-46 \% \\
(21 \cdot 1 \pm 12 \cdot 4 \%) \\
27-78 \\
(42 \pm 24) \\
50->180\end{array}$ \\
\hline
\end{tabular}


to small to large lingual to sublingual thyroid in the thyroglossal duct to enlarged thyroid in normal location. Measurement of gland uptake provided interesting additional information on the functional status of the gland. The uptake technique described is fairly simple and does not correct for variations in gland depth or for non-uniformity across the detector face. Of these two sources of error, a variation in gland depth is the most important giving rise to errors of $\pm 40 \%$ in certain circumstances. The overall accuracy of the uptake results is probably not greater than $\pm 50 \%{ }^{9}$ Despite this, the uptake results provide a good indication of gland trapping and allow a clear distinction to be made in cases of apparent dyshormonogenesis. The high uptake observed in some of the lingual thyroids (up to $6 \%$ ), suggests the possibility that dyshormonogenesis may coexist with failure of the gland to descend. Since no normal euthyroid neonates have been scanned it is not possible to compare the uptake results with those expected in a normal comparable population. However, a review of results obtained using ${ }^{131} \mathrm{I}$ indicated that after 3-5 days post-partum, the gland uptake of ${ }^{131} \mathrm{I}$ is essentially similar to that of the adult and on that basis one can assume a ${ }^{99} \mathrm{~m}$ Tc uptake of $1-4 \%$ in the euthyroid neonate..$^{15}$ Using this normal range, about $24 \%$ of all neonates with evidence of functional tissue had a 'normal' uptake of ${ }^{99 \mathrm{~m} T c}$. Thus uptake alone identifies only poorly neonates with CHT.

The results (Table 1) indicate that there is little correlation between the biochemical findings and either gland anatomy or function. However, all athyreotic neonates had TSH levels greater than $180 \mathrm{mU} / 1$, so that a lower TSH level indicates the presence of some functioning thyroid tissue. Interestingly the presence of thyroxine in the neonatal serum does not appear to imply the existence of detectable functioning thyroid tissue. The origin of this thyroxine is a matter for speculation as it is currently accepted that there is a little or no transfer of thyroxine or TSH from the maternal circulation across the placenta. ${ }^{16}$ Very small thyroid elements may not be detectable. Alternatively ectopic thyroid tissue may have failed to function after birth. The variation in the thyroid anatomy observed in neonates in Ireland was similar to that observed by Connolly et al. ${ }^{3}$ in Australia, and by Walfish et al. ${ }^{6}$ in Canada. The difference between these results and those of Fisher ${ }^{1}$ can perhaps be explained by the length of time between birth and the scan.

Intermediate hormone replacement therapy will undoubtedly alter the stimulus (TSH) to the thyroid tissue and may cause it to regress.

Stopping the hormone therapy and allowing the TSH levels to rise 1 to 2 weeks before scanning may not result in an anatomical and functional picture identical with that observed at birth. This theory is supported by our findings in 1-year-old children in whom there is a far higher incidence of apparent agenesis $(67 \%)$ compared with neonates $(28 \%)$. Unfortunately, as there were so few cases, these findings cannot be more than tentative.

One of the most important considerations in thyroid scanning is the radiation dose delivered to the neonate. A reduction in the administered dose of ${ }^{99 \mathrm{~m}} \mathrm{Tc}$ requires a corresponding increase in scanning time. This increase carried with it the associated problem of restraining the neonate for the scanning period. The moulding technique described above did not require sedation and was well tolerated. However, 1-year-old children generally dislike being restrained and usually cry. Despite this, in no case did the mould fail to restrain movement of the infants during the 30-minute scanning period.

Measurement of gland uptake of $99 \mathrm{~m} \mathrm{Tc}$, together with an estimate of gland mass from the scan, provide further information on the radiation dose to the gland. As with gland uptake the estimate of gland mass is recognised as being inaccurate with a possible error of $\pm 100 \%{ }^{11}$ Despite this, we believe that these results provide valuable dosimetric data on the radiation dose to the neonatal thyroid. Fig. 2 shows the range of absorbed doses to the glands, from which it can be seen that about $70 \%$ of the neonates received thyroid doses of less than $3.0 \mathrm{mGy}$. Such a dose must be compared with that delivered by a conventional neonatal chest $x$-ray film, where the surface skin dose over the thyroid is of the order of $0.5 \mathrm{mGy}(50 \mathrm{mR})$ or greater. ${ }^{14}$ All the high doses in Fig. 2 were given to neonates with normally located enlarged glands and high uptakes of ${ }^{99 \mathrm{~m} T c}$. Clinical notes on these neonates showed that in some of them goitres had been detected at birth. In such cases gland anatomy and function can be inferred from the clinical picture and scanning may not be required. If performed a reduction in the administered dose of ${ }^{99 \mathrm{~m} T c}$ from $1.85-3.7 \mathrm{MBq}$ to 0.9-1.8 MBq would still allow adequate scanning of the gland. In the general case, a reduction of the dose below 1.85-3.7 MBq is not feasible because of the low ratio $(2: 3)$ of neonatal/room background activity seen by the gamma camera and the corresponding increase in scanning time required.

A further dosimetric consideration in favour of scanning is that most neonates with $\mathrm{CHT}$ will be on hormone replacement therapy for the rest of their lives. Consequently the function of any thyroid tissue present will be suppressed by the exogenous hormone and any irradiated cells in the gland will not be subjected to TSH stimulation. Many investigators have demonstrated, in animals, that the 
effects of radiation on the thyroid gland are greatly reduced in the absence of TSH stimulation. ${ }^{17} 18$

The low doses used should allow further scanning assessments in later life. This could be especially useful in transient cases and in assessing the development or possible involution of gland function. This is one aspect of CHT for which little information is available.

Thus, dosimetrically, neonatal thyroid scanning can be a fairly safe procedure. However, how necessary and how useful is a thyroid scan? Diagnosis can be confirmed biochemically and there is the reasonable argument that a thyroid scan merely confirms the biochemical finding and imposes a radiation burden, albeit a small one, on the human body during one of its most radiosensitive phases. In reply to this argument it must be said that in many of the neonates scanned no clinical features of CHT were evident ${ }^{5}$ and clinicians were often less than fully convinced of the biochemical diagnosis unti confronted with a positive scan finding. Furthermore, definitive proof of a thyroid disorder, as provided by scanning, permits the clinician to proceed with the treatment with confidence, and also allows him better to assess the short and long-term needs of the infant.

We thank the staff of the National Metabolic Screening Laboratory, Temple Street Hospital, particularly Dr S Cahalane and Dr S Dockeray who referred the patients, and Mr Aidan Cranny and colleagues of the Endocrinology Laboratory, St James's and Federated Hospitals, who carried out the serum hormone assays.

\section{References}

1 Fisher D A. Status of neonatal hypothyroid screening. Report from the Quebec International Conference on Neonatal Thyroid Screening. In: Stockigt J R, Nagataki S, eds. Thyroid research VIII. Proceedings of the Eighth International Thyroid Congress, Sydney, Australia 1980. Canberra: Australian Academy of Sciences, 1980: 1-7.

2 Walsh M P. Screening for neonatal hypothyroidism. BrJ Hosp Med 1979; 21 : 28-36.

3 Connolly J F, Gold H, Klempfner G, Mathur K S, Warne G L, Wettenhall $\mathbf{H}$ N B. Scanning with ${ }^{89} \mathrm{mTc}$ pertechnetate in assessment of hypothyroid babies detected by neonatal screening. In: Stockigt $\mathbf{J} \mathbf{R}$, Nagataki S, eds. Thyroid Research VIII. Proceedings of the Eighth International Thyroid Congress, Sydney, Australia 1980. Canberra: Australian Academy of Sciences, 1980: 30-2.
4 Illig R. Neonatal screening for hypothyroidism by TSH determination in dried blood. In: Bickel $\mathbf{H}$, Guthrie $\mathbf{R}$, Hammersen G, eds. Neonatal screening for inborn errors of metabolism. Berlin: Springer, 1980: 179-89.

5 Dockeray S, Cahalane S F, Brody M, Mullins C, Cullen M J. Screening for congenital hypothyroidism in the Republic of Ireland. Br Med J 1980; 281 : 1519-22.

- Walfish S G, Ginsbery J, Howard N J. Results of the Toronto regionalized screening program for detecting neonatal hypothyroidism. In: Bickel $\mathbf{H}$, Guthrie $\mathbf{R}$, Hammersen G, eds. Neonatal screening for inborn errors of metabolism. Berlin: Springer, 1980: 207-17.

7 Roedler H D, Kaul A, Hine G J. Internal radiation dose in diagnostic nuclear medicine. Berlin: Hoffmann, 1978: 15-27.

8 Maisey M N, Natarajan T K, Hurley P J, Wagner H N, Jr. Validation of a rapid computerised method of measuring ${ }^{99} \mathrm{mTc}$ pertechnetate uptake for routine assessment of thyroid structure and function. J Clin Endocrinol Metab 1973; 36: 317-22.

9 O'Connor M K, Malone J F. Thyroid uptake measurements: the influence of gland depth, gland mass, and lobe separation. Br J Radiol 1978; 51 : 454-9.

10 Armstrong D I, Rogers T G H, Brownlie B E W. Computer assisted thyroidal technetium uptake measurement using a short pinhole to surface distance. $A J R$ 1975; 123: 60-6.

11 Mandart G, Erbsmann F. Estimation of thyroid weight by scintigraphy. Int J Nucl Med Biol 1975; 2 : 185-8.

12 Shepard T H. Development of the human fetal thyroid. Gen Comp Endocrinol 1968; 10: 174-81.

13 Documenta Geigy. In: Diem K, ed. Scientific tables. Manchester: Geigy, 1962: 608.

14 Webster E W, Alpert N M, Brownell G L. Radiation doses in pediatric nuclear medicine and diagnostic $x$-ray procedures. In: James A E, Wagner H N, Cooke R E, eds. Pediatric nuclear medicine. Philadelphia: Saunders, 1974: 34-58.

15 Mosier H D, Jr. Interpretation of thyroid function tests. In: Gardner L I, ed. Endocrine and genetic disease of childhood and adolescence. Philadelphia: Saunders, 1975: 330-47.

16 Ragazzini F. Congenital hypothyroidism. In: La Cauza C, Root W A, eds. Problems in pediatric endocrinology. London: Academic Press, 1980: 155-68.

17 Doniach I. Experimental induction of tumours of the thyroid by radiation. $\mathrm{Br}$ Med Bull 1958; 14: 181-3.

18 Lindsay S. Ionising radiations and experimental thyroid neoplasms. In: Hedinger C E, ed. Thyroid cancer. London: Heinemann, 1969: 161-71.

19 Atkins H L, Klopper J F. Measurement of thyroidal technetium uptake with the gamma camera and computer system. AJR 1973; 118: 831-5.

Correspondence to Dr M K O'Connor, Department of Radiology/Nuclear Medicine, St James's Hospital, Dublin 8, Ireland.

Received 3 March 1982 